Journal of Sport Coaching and Physical Education 3 (1) (2018)

\title{
ANALISIS KETERAMPILAN TEKNIK BERMAIN SEPAKBOLA MAHASISWA PENDIDIKAN KEPELATIHAN OLAHRAGA FIK UNNES
}

\section{Purwono Sidik Permono}

Jurusan Pendidikan dan Kepelatihan Olahraga, Fakultas Ilmu Keolahragaan, Universitas Negeri Semarang, Indonesia

\section{Info Artikel}

Sejarah Artikel: Diterima Juli 2018

Disetujui Juli 2018

Dipublikasikan Agustus 2018

Keywords:

basic technique of football

\begin{abstract}
Abstrak
Tujuan penelitian: mengetahui keterampilan teknik bermain sepakbola pada mahasiswa Pendidikan Kepelatihan Olahraga FIK UNNES. Metode penelitian survei dengan pendekatan diskriptif, teknik pengambilan data dengan tes. Desain penelitian one-shot case study. Sampel penelitian peserta mata kuliah Ilmu Kepelatihan Khusus Sepakbola 1 Jurusan PKLO FIK UNNES yang berjumlah 30 siswa. Teknik penarikan sampel menggunakan Total Sampling. Hasil analisis keterampilan teknik bermain sepakbola mahasiswa Pendidikan Kepelatihan Olahraga FIK UNNES, Hasil analisis menunjukkan pada keterampilan juggling, nilai rata-rata 6.63 kategori cukup, pada keterampilan passing rata-rata 6.47 kategori cukup, pada keterampilan shooting, nilai rata-rata 76.67 kategori cukup. Dan pada keterampilan dribbling nilai rata-rata 23 kategori cukup. Saran: 1) Keterampilan teknik dasar bermain sepakbola siswa yang berkenaan dengan juggling, passing, shooting, dan dribbling harus ditingkatkan lagi dengan program pembelajaran yang lebih baik sesuai dengan teknik dasar bermain sepakbola. 2) Materi perkuliahan yang telah ada sekarang perlu dievaluasi secara terus menerus agar menjadi sebuah materi yang tersusun satu kesatuan yang lebih baik dan prestasi yang dicapai menjadi maksimal. 3) Pengembangan bahan ajar sepakbola yang disesuaikan dengan kurikulum dan kebutuhan di dunia kerja.
\end{abstract}

\begin{abstract}
Research objectives: knowing the technique skills students at play football Sports Coaching Education FIK UNNES.The method of this research is the descriptive approach, the technique data use the test. Design research of one-shot case study. Sample research participants of Ilmu Kepelatihan Khusus Sepakbola 1 PKLO FIK UNNES that add up to 30 students. The Sample technique using Total Sampling. The results of the analysis of the skills of technique students play football Sports Coaching Education FIK UNNES, the results of the analysis show the skills of juggling, the average value of 6.63 is enough, on average passing skill 6.47 is enough, on skill of shooting, the average rating 76.67 is enough. Dribbling skills and on the average value of 23 is enough. Suggestions: 1 basic technique Skills play football students who deal with juggling, passing, shooting, and dribbling should be improved with a better learning programme in accordance with the basic techniques of playing football. 2) Lecture Materials that have been there now needs to be evaluated continuously in order to become a material composed a better unity and achievements reached into maximum. 3 learning materials Development football tailored to the curriculum and the needs of the world of work.
\end{abstract}

(C) 2018 Universitas Negeri Semarang

\footnotetext{
Alamat korespondensi:

Gedung F1 Lantai 3 FIK UNNES

Kampus Sekaran, Gunungpati, Semarang, 50229

E-mail: jscpe.pklo@unnes.ac.id
}

ISSN 2548-4885 


\section{PENDAHULUAN}

Olahraga merupakan salah satu cara untuk menjaga agar kesegaran jasmani tetap berada dalam kondisi yang baik. Sehingga terlihat pria maupun wanita, tua atau muda melakukan olahraga, ini mereka lakukan agar kesehatan dan kesegaran jasmani tetap baik yang digunakan sebagai dasar penting untuk hidup bahagia dan bermanfaat. Hakikat olahraga merupakan kegiatan fisik yang mengandung sifat permainan dan berisi perjuangan melawan diri sendiri atau melawan orang lain atau konfrontasi dengan unsur-unsur alam. Kegiatan olahraga meliputi gaya pertandingan, maka kegiatan itu harus dilaksanakan dengan semangat atau jiwa sportif.

Sepakbola merupakan permainan beregu, masing-masing regu terdiri dari sebelas pemain, dan salah satunya penjaga gawang. Permainan ini hampir seluruhnya dimainkan dengan menggunakan tungkai kecuali penjaga gawang yang diperbolehkan menggunakan lengannya didaerah tendangan hukumannya. Sepakbola berkembang dengan pesat di kalangan masyarakat, karena permainan ini dapat dimainkan oleh laki-laki dan perempuan; anak-anak, dewasa; dan orang tua (Sucipto, dkk, 1999/2000:7)..

Jurusan pendidikan kepelatihan olahraga FIK UNNES merupakan lembaga dan organisasi yang tersusun rapi. Segala kegiatan direncanakan dan diatur sesuai dengan kurikulum. Dan untuk menghadapi kemajuan jaman kurikulum selalu diadakan perubahan, diperbaiki dan disempurnakan agar apa yang diberikan di bangku kuliah terhadap calon-calon pendidiknya dapat digunakan untuk menghadapi tantangan hidup di masa sekarang maupun yang akan datang, sehingga sekolah sebagai tempat untuk belajar agar tujuan hidup atau citacitanya tercapai.

Di jurusan pendidikan kepelatihan olahraga FIK UNNES ada satu matakuliah pilihan yang harus diambil oleh mahasiswa semester 4 untuk menekuni atau mempelajari satu cabang olahraga pilihan. Matakuliah ilmu kepelatihan khusus (IKK) menawarkan beberapa cabang olahraga yang disesuaikan dengan kebutuhan masyarakat di lapangan. Salah satu matakuliah IKK yang paling banyak diminati mahasiswa adalah IKK sepakbola. Hasil wawancara peneliti dengan beberapa mahasiswa yang mengikuti kegiatan belajar pada matakuliah IKK sepakbola, bahwa cabang olahraga sepakbola bagi mereka merupakan hobi dan ketekunan sejak kecil. Berdasarkan latar belakang masalah yang telah diuraikan, maka menjadi dasar penelitian yang akan dilaksanakan penulis dengan judul "Analisis Keterampilan Teknik Bermain Sepakbola pada Mahasiswa Pendidikan Kepelatihan Olahraga FIK UNNES"

\section{METODE PENELITIAN}

Pada penelitian ini jenis
penelitiannya diskribtif, dan Metode yang digunakan dalam penelitian ini adalah metode survei dan teknik tes. Desain penelitian yang digunakan adalah desain one-shot case study. Adapun desain yang dimaksud digambarkan sebagai berikut:

Populasi dalam penelitian ini adalah seluruh mahasiswa mata kuliah Ilmu Kepelatihan Khusus Sepakbola 1 jurusan Pendidikan Kepelatihan Olahraga FIK UNNES. Sampel dari 
penelitian ini adalah mahasiswa mata kuliah Ilmu Kepelatihan Khusus Sepakbola 1 jurusan Pendidikan Kepelatihan Olahraga FIK UNNES yang berjumlah 30 mahasiswa. Teknik pengambilan sampel pada penelitian ini menggunakan Tota Sampling. Instrument yang digunakan dalam penelitian ini adalah tes keterampilan Sepakbola yang meliputi: 1) keterampilan Juggling, 2) keterampilan passing, 3) keterampilan Shooting, 4) ketereampilan Dribbling.

\section{HASIL PENELITIAN DAN PEMBAHASAN}

Hasil penelitian dari Analisis Keterampilan Teknik Bermain Sepakbola pada Mahasiswa Pendidikan Kepelatihan Olahraga FIK UNNES. Dari hasil penelitian dapat dilihat sebagai berikut:

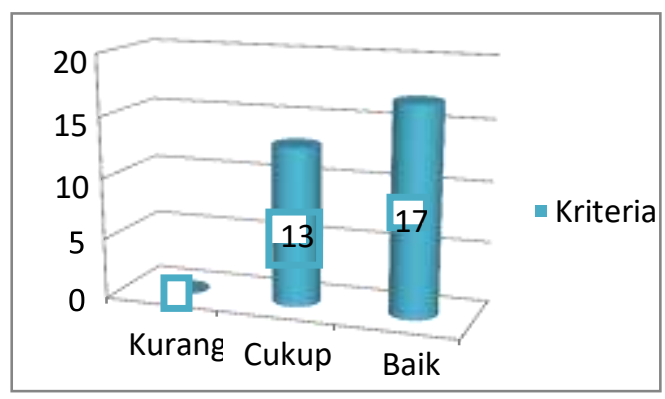

Grafik 1. Penilaian Hasil Tes Teknik Juggling

Dari grafik di atas, jelas terlihat bahwa kriteria baik adalah kriteria hasil tes juggling mahasiswa Pendidikan Kepelatihan Olahraga FIK UNNES yang terbanyak yaitu dengan jumlah 17 orang. Jadi dapat disimpulkan bahwa keterampilan teknik juggling mahasiswa Pendidikan Kepelatihan Olahraga FIK UNNES yaitu mendapat kriteria cukup, dengan skor rata-rata yaitu 41.57.

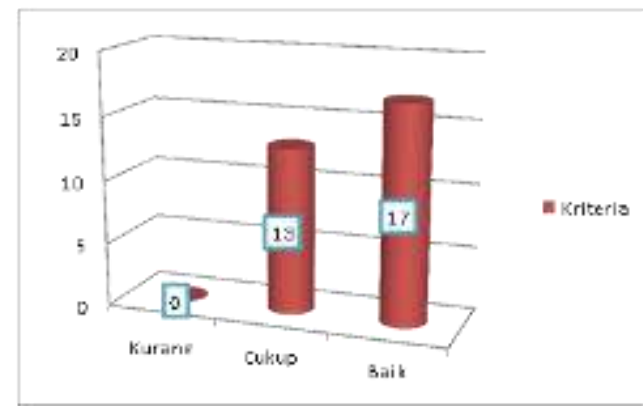

Grafik 2. Penilaian Hasil Tes Teknik Passing.

Dari grafik di atas, dapat terlihat juga bahwa kriteria baik adalah kriteria dominan yang terdapat pada tes passing yaitu dengan total 17. Dapat disimpulkan bahwa keterampilan teknik passing mahasiswa Pendidikan Kepelatihan Olahraga FIK UNNES yaitu mendapat kriteria cukup, dengan skor rata-rata yaitu 6.47 .

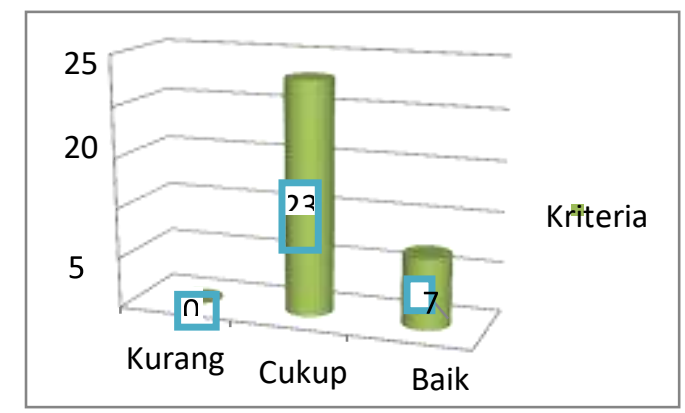

Grafik 3. Penilaian Hasil Tes Teknik Shooting

Dari grafik di atas, dapat terlihat juga bahwa kriteria baik adalah kriteria dominan yang terdapat pada tes shooting yaitu dengan total 23. Dapat disimpulkan bahwa kriteria cukup adalah kriteria hasil tes shooting mahasiswa Pendidikan Kepelatihan Olahraga FIK UNNES yaitu mendapat kriteria cukup, dengan skor rata-rata yaitu 110 . 


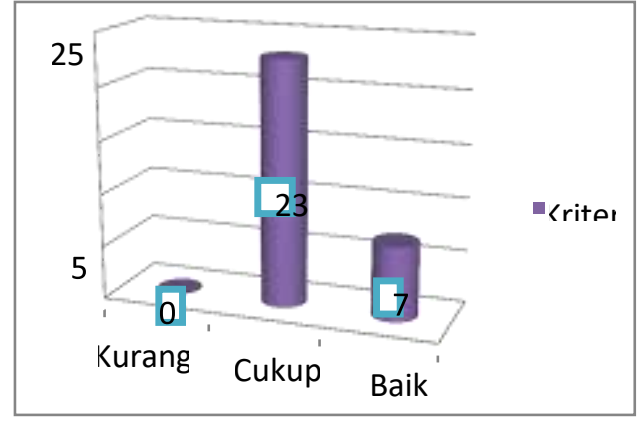

Grafik 4. Penilaian Hasil Tes Teknik Dribbling

Dari grafik di atas, dapat terlihat juga bahwa kriteria baik adalah kriteria dominan yang terdapat pada tes dribbling yaitu dengan total 23. Jadi dapat disimpulkan bahwa keterampilan teknik dribbling mahasiswa Pendidikan Kepelatihan Olahraga FIK UNNES yaitu mendapat kriteria cukup, dengan masingmasing nilai rata-rata yaitu 23.2 detik.

\section{SIMPULAN}

Berdasarkan hasil penelitian dan pembahasan yang telah diuraikan, maka dapat ditarik simpulan, pada hasil tes juggling didapat nilai rata-rata kriteria cukup, adapun kriteria dominan yaitu 17 atau $56.67 \%$ mendapat nilai baik, pada hasil tes passing didapat nilai rata-rata kriteria cukup, adapun kriteria dominan yaitu 17 atau $56.67 \%$ mendapat nilai baik, pada hasil tes shooting didapat nilai rata-rata kriteria cukup, adapun kriteria dominan yaitu 23 atau $76.67 \%$ mendapat nilai cukup, pada hasil tes dribble didapat nilai rata-rata kriteria cukup, adapun kriteria dominan yaitu 23 atau $76.67 \%$ mendapat nilai cukup. Berdasarkan simpulan diatas, maka peneliti memberikan saran sebagai berikut: 1 . Keterampilan teknik dasar bermain sepakbola siswa yang berkenaan dengan juggling, passing, shooting, dan dribbling harus ditingkatkan lagi dengan program pembelajaran yang lebih baik sesuai dengan teknik dasar bermain sepakbola. 2. Materi perkuliahan yang telah ada sekarang perlu dievaluasi secara terus menerus agar menjadi sebuah materi yang tersusun satu kesatuan yang lebih baik dan prestasi yang dicapai menjadi maksimal. 3. Pengembangan bahan ajar sepakbola yang disesuaikan dengan kurikulum dan kebutuhan di dunia kerja.

\section{DAFTAR PUSTAKA}

Arikunto, Suharsimi. 2002. Prosedur Penelitian; Suatu Pendekatan Praktek.Jakarta; Rineka Cipta.

Depdiknas. 2006. Perencanaan Dan Disain Kurikulum Dalam Pendidikan Jasmani. Jakarta. Depdikbud. P2LPTK. . 2004. Buku Pegangan Penggunaan Perlatan Olahraga Anak (POA).

Jakarta, Direktorat IPTEK- Dirjen Olahraga. 2002. Buku VI Sepak Bola Mini. Jakarta. Dirjen Dikdasmen. Direktorat Pendidikan Taman Kanak-Kanak dan Sekolah Dasar.

Hadi, Sutrisno. 2004. Metodologi Research Jilid 1. Jogjakarta. Andi Offset.

Muhajir. (2004). Pendidikan Jasmani Teori dan Praktek. Jakarta: Erlangga. Jakarta. Arcan.

Roji. 2006. Pendidikan Jasmani, Olahraga dan Kesehatan Kurikulum Satuan Tingkat Pendidikan. Jakarta. Penerbit Erlangga

Sucipto dkk, 2000. Sepak Bola . Depdikbud: Dirjendikti

Suwarno. KR. (2001). Sepakbola: Gerak Dasar dan Teknik Dasar. Yogyakarta. FIK UNY. 